\title{
ERRATA da Tese: Alguns estudos da fluorescência e quimiluminescência de substâncias húmicas
}

- Na página 18, primeiro parágrafo, onde se lê peso molecular, leia-se massa molecular.

- Na página 21, último parágrafo, onde se lê a quantidade de cargas negativas na molécula de substância húmica aumenta, leia-se a quantidade de cargas negativas na molécula de substância húmica diminui.

- Na página 35, terceiro parágrafo, onde se lê: absorção em $430 \mathrm{~nm}$, leia-se: absorção em $300 \mathrm{~nm}$.

- Na página 43, terceiro parágrafo, onde se lê: ROCHA, J.C., Aquatic humus from an unpolluted Brazilian dark-brown stream: general characterization and size fractionation on bound heavy metals. Journal of Environmental Monitoring 2, 39-44, 2000, leia-se: ROCHA, J.C., SENE, J.J., SANTOS, A., TOSCANO, I.A.S. e ZARA, L.F., Aquatic humus from an unpolluted Brazilian dark-brown stream: general characterization and size fractionation on bound heavy metals. Journal of Environmental Monitoring 10, 39-44, 2000.

- Na página 64 , Tabela 2.1, onde se lê $\underline{C c\left(m o l . g^{-1}\right)}$, leia-se $\underline{C c\left(m m o l . g^{-1}\right)}$.

- Na página 64, Tabela 2.1, onde se lê $\underline{K \times 10^{3}}$, leia-se $\underline{K / 10^{3}}$.

- Na página 71, segundo parágrafo, onde se lê (tabela 1.2, p. 37), leia-se (p. 35, terceiro parágrafo). 